\title{
Evaluation of appliances mobile controller system using expectation-confirmation theory model
}

\author{
Aslina Baharum', Chew Yun Fai ${ }^{2}$, Rozita Ismail ${ }^{3}$, Ismassabah Ismail ${ }^{4}$, Farhana Diana Deris ${ }^{5}$, Noorsidi \\ Aizuddin Mat Noor ${ }^{6}$ \\ ${ }^{1,2}$ User Experience Research Lab (UXRL), Faculty of Computing and Informatics, Universiti Malaysia Sabah, 88400 \\ Kota Kinabalu, Sabah, Malaysia \\ ${ }^{3}$ College of Computing and Informatics, Universiti Tenaga Nasional, Putrajaya Campus, Malaysia \\ ${ }^{4}$ Centre of Foundation Studies, Universiti Teknologi MARA Cawangan Selangor, Kampus Dengkil, 43800 Dengkil, \\ Selangor, Malaysia \\ ${ }^{5}$ Faculty of Social Sciences and Humanities, Universiti Teknologi Malaysia, Malaysia \\ ${ }^{6}$ UTM CRES, Faculty of Built Environment and Surveying, Universiti Teknologi Malaysia, Johor Bahru, Johor, \\ Malaysia
}

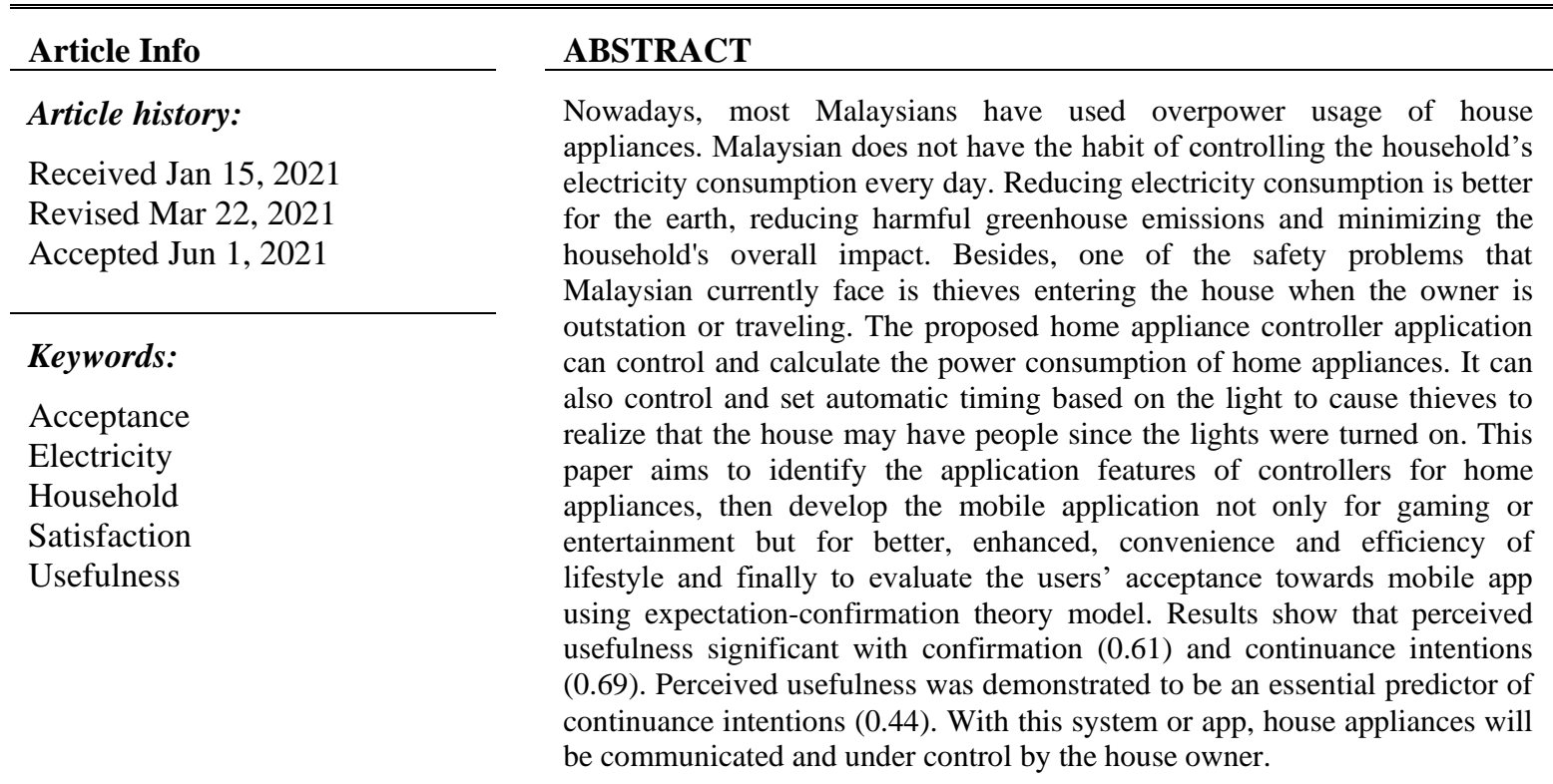

This is an open access article under the CC BY-SA license.

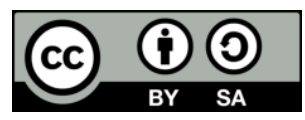

\section{Corresponding Author:}

Aslina Baharum

UXRL, Faculty of Computing and Informatics

Universiti Malaysia Sabah

88400 Kota Kinabalu, Sabah, Malaysia

Email: aslina@ums.edu.my

\section{INTRODUCTION}

Mobile technologies like smartphones and tablets have transformed our lives. Smartphones and tablets are great; they are a computer in our pockets packed full of features to make our lives easier [1]. Our lives are so involved around our smartphones and tablets until we might drive back home to retrieve it if we end up somewhere without it [2]-[4]. So, the idea comes out with to use of one mobile device to communicate with whole-house appliances. 
Household electricity consumption has a huge impact on the environment nowadays. Air conditioning is one of the home appliances with the most electricity consumption [5]. A survey questionnaire on the behavior of natural ventilation in multi-storey houses was conducted in 2005 . The respondents were Malaysians; almost $62 \%$ had at least one air conditioner in this survey [6]. The results show a significant relationship between the average monthly household income and the number of air conditioners among households [6]. Thus, it suggests that the more monthly income they earn, the more air conditioners they have [7]. These results show that Malaysians do not consider energy saving to be right. Reducing emissions has become an important orientation of environmental policy around the world [7].

Besides, the overall crime rate is set as high for Malaysia. Petty crimes against expatriates are common, while violent crimes are still rare [8]. There was an increase in crime in Kuala Lumpur in 2014. Including some reported attacks and robberies, they sometimes involved weapons. Petty theft, especially confiscation of wallets and pickpockets and home theft, are the most common crimes committed against foreigners. Other types of nonviolent criminal activity include credit card fraud and vehicle theft [8]. All this shows that the crime situation and the security of Malaysia are placed high, and the Government's concern about the crime is happening because the crime rate in Malaysia has reached the highest level.

In conclusion, household electricity consumption over consumption can be controlled with the power usage monitoring method. The safety of the house to avoid theft can be controlled if setting the time for the house appliances on and off to make the robbery confused with the house owner's present in the house. Even though there are a few current systems available in the current market, there is still a limitation on evaluating the developed system. Thus, the expectation-confirmation theory will be used to evaluate the user acceptance of the developed system.

\section{RELATED STUDIES}

Home appliances are electrical or mechanical machines that perform household functions [9], such as cooking or cleaning. More specifically, Collins's dictionary defines "household appliances" as: "devices or machines, usually electrical, that are in your home and which you use to do jobs." [10]. The house appliance control system is controlled either by an Android, iOS app with Android, iOS devices, or by a PC. House appliances are connected to a server through a USB trigger. Mobile apps and personal computers are accessing the server to control the house appliances. It controls various appliances such as light, fan, auto gate, security door, CCTV. Home appliance control systems or applications receive commands from remote devices manipulated by the user. The system or application then sends a command to the respective equipment to act [11].

Mobile applications are software applications designed to run on mobile devices such as smartphones and tablets. The term "application" is an abbreviation of the term "application software". These have become very popular and was in 2010 listed as "Word of the year" by the American dialect society [12] in 2009. The use of mobile applications is becoming increasingly prevalent among mobile phone users [13]. Therefore, using mobile applications to control home appliances would be an excellent innovation for current trends.

\subsection{Expectations-confirmation theory}

Expectation-confirmation theory (ECT) is a cognitive theory that aims to explain post-purchase or post-adoption satisfaction as a function of expectations, perceived performance, and disconfirmation of beliefs [14], [15]. The four main constructs in the model are expectations, performance, disconfirmation, and satisfaction. To evaluate users' acceptance towards mobile apps using the expectation-confirmation theory model after the control appliance app prototype is released. ECT or expectation-disconfirmation theory (EDT) is a cognitive theory widely applied in information system (IS) to determine continuance usage intention besides studying user satisfaction. Figure 1 presents the framework of ECT.

Based on Figure 1, the users have an initial expectation of a specific product or service. Then, they will accept and use it. After a period of use, they will form perceived usefulness regarding the product or service and determine their extent to which their expectation is confirmed [16]. Based on their confirmation level, they will give the satisfaction level and decide either to continue or discontinue its subsequent use. From these figures, it is shown that lower expectations and/or higher performance lead to more significant validation, which increases customer satisfaction and intention to proceed. Thus, confirmation is related to expectations and directly related to perceived usefulness.

EECT argues that users 'intentions for continuous use of information systems depend on three main variables: satisfaction, perceived usefulness, and continuance intention. This theoretical model is believed to explain continuance intention's determination as applied to users' use of appliances mobile controller system using smartphone and tablet. Figure 1 depicts the relationships and corresponding hypotheses involved in 
users' continuance intention model. After prototyping is developed, then users' acceptance using ECT model will be conducted.

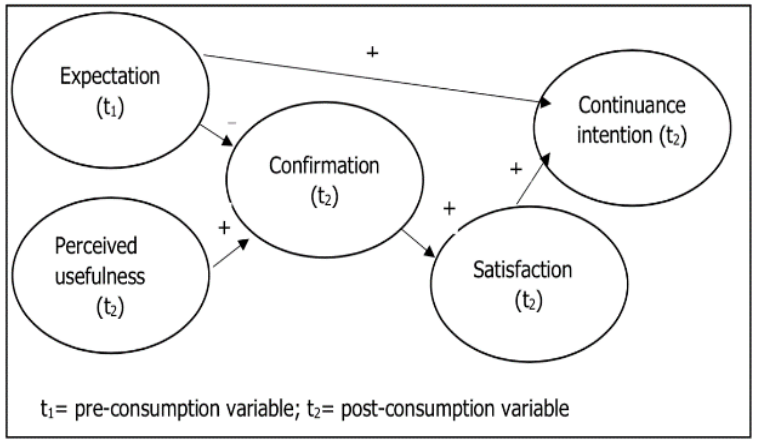

Figure 1. Expectation-confirmation theory

\section{RESEARCH METHOD}

Table 1 consists of four phases based on the specific four objectives that will be achieved using different methods. In phase 1, the questionnaire is used to get the information of the power usage of the house appliances among the users through preliminary study and literature review method. For phase 2 and 3 , using the evolutionary prototyping method to design and develop the web-based and mobile applications, namely as HomeBot [14]. Phase 4 evaluates the users' acceptance towards mobile applications using the expectation confirmation theory model method by conducting a survey.

Table 1. Summary of research method

\begin{tabular}{cllll}
\hline Phase & \multicolumn{1}{c}{ Description } & \multicolumn{1}{c}{ Method } & Objective \\
\hline 1 & $\begin{array}{l}\text { Questionnaire for the users to get the } \\
\text { information on the power usage of the house } \\
\text { appliances }\end{array}$ & $\begin{array}{l}\text { Preliminary Study } \\
\text { Literature Review }\end{array}$ & $\begin{array}{l}\text { To identify the power usage of the house } \\
\text { appliances among the users using a literature } \\
\text { review. } \\
\text { Design the user-interface and the features of } \\
\text { the house appliances' control mobile app } \\
\text { system }\end{array}$ & $\begin{array}{l}\text { To design the web-based system. And, to } \\
\text { develop the mobile app using Evolutionary }\end{array}$ \\
& $\begin{array}{l}\text { Survey on the users' acceptance after using } \\
\text { the house appliances' control mobile app }\end{array}$ & $\begin{array}{l}\text { Expectation-Confirmation } \\
\text { Theory model method }\end{array}$ & $\begin{array}{l}\text { To evaluate the users acceptance towards } \\
\text { mobile app using Expectation Confirmation } \\
\text { Theory model. }\end{array}$ \\
\hline
\end{tabular}

The data are collected through a questionnaire survey. The target population consists of non-specific respondents. The responses are gathered according to appropriate questionnaire items, at which respondents will be given a statement and a scale to respond with. Confirmation is then being measured through the users' evaluation. Confirmation is carried out to measure the degree to which users experience mobile controller systems using smartphones and tablets before and after users experience the mobile controller system. The confirmatory factor analysis is used to pairwise correlate the measurements. The estimation is performed using procedure Calis and the maximum likelihood method. Confirmation is also being measured by collecting data on consumers' complaints, word-of-mouth, and observing the continuance intention trend to improve the products. Figure 2 shows the expectation-confirmation theory model.

- Hypothesis 1 (H1): Confirmation is positively associated with users' perceived usefulness of the appliances mobile controller system using smartphones and tablets.

- Hypothesis 2 (H2): Users' extent of confirmation is positively associated with their satisfaction with the usefulness of the appliances mobile controller system using smartphones and tablets.

- Hypothesis 3 (H3): Users' perceived usefulness with appliances mobile controller systems using smartphones and tablets is positively associated with their satisfaction with the use of appliances mobile controller systems using smartphones and tablets.

- Hypothesis 4 (H4): Users' continuance intention is positively associated with their perceived usefulness of the mobile controller system using smartphones and tablets.

- Hypothesis 5 (H5): Users' satisfaction with the use of appliances mobile controller system using smartphone and tablet is positively associated with their appliances mobile controller system using smartphone and tablet continuance intention. 


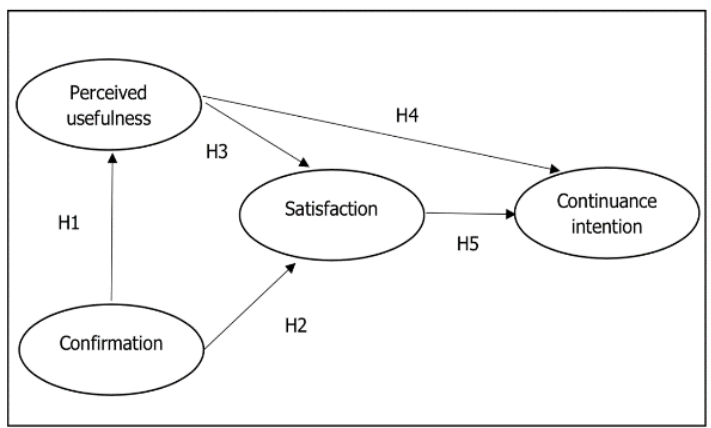

Figure 2. Expectation-confirmation theory model

\subsection{System analysis}

The first objective, to identify the power usage of the house appliances that are generally used among the users using a preliminary study and literature review. A survey was conducted for Malaysians on household energy consumption in modern homes in Malaysia [15], such as Johor Baharu and Kuala Lumpur. Respondents consists of 64\% Malays, 28\% Chinese and Indians 7\%, which is almost equal to the nation's average rate. Figure 3 to Figure 4 show the level of ownership of the household appliances survey in 2009. As shown, almost all respondents owned at least one unit of the first five items; television, refrigerator, washing machine, rice cooker and ceiling fan.

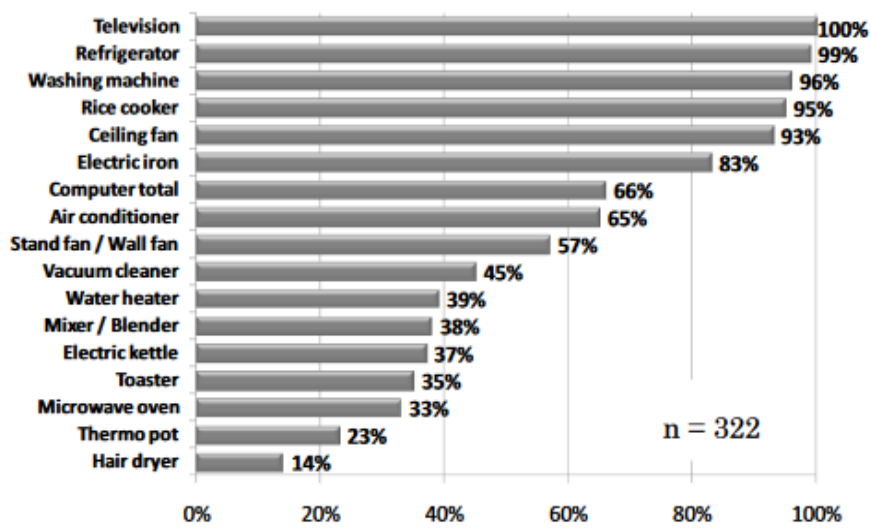

Figure 3. Ownership level

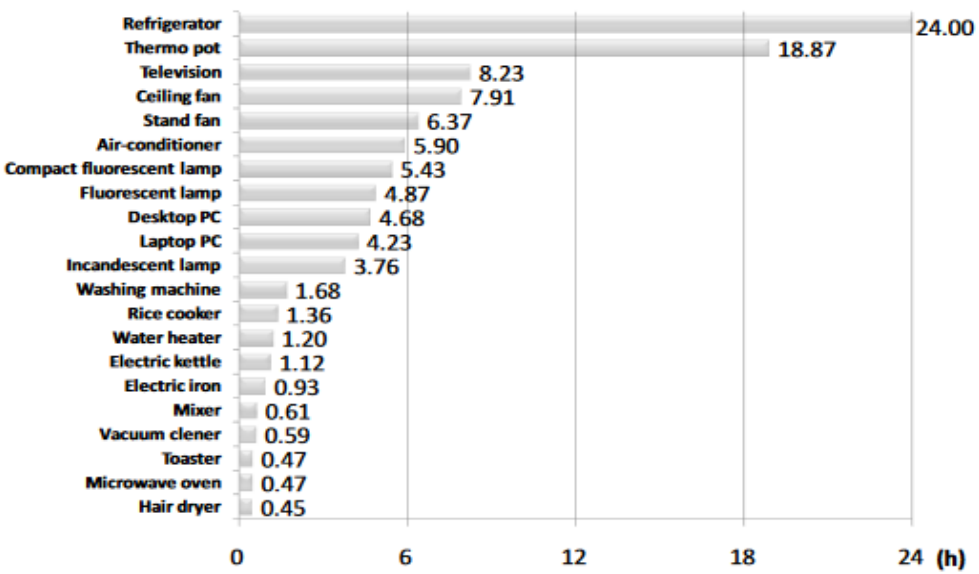

Figure 4. Daily usage time 
Figure 5 shows the average daily usage time of the respective appliances. Annual electricity consumption is calculated for each appliance based on the amount, time of use, and the goods' electrical capacity. Malaysia experiences a hot, humid climate throughout the year and air temperatures and monthly humidity are almost constant in most urban areas. Therefore, the pattern of use of household appliances is considered to be continuous throughout the year. The results showed that air conditioning was the most important contributor, recording an average electricity consumption of $1,167 \mathrm{kWh}$ [17]. In the results, the survey shows the structure of household energy consumption in modern Malaysian special houses.

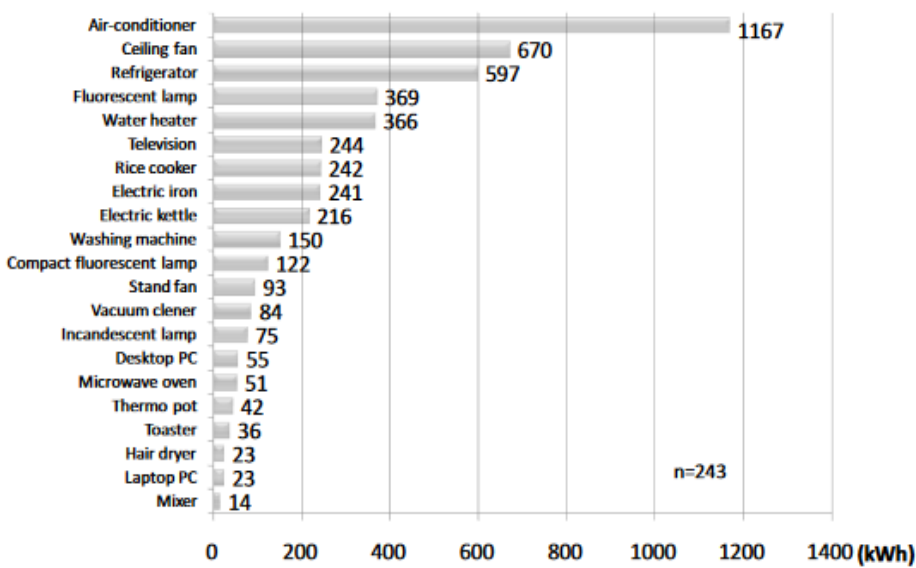

Figure 5. Yearly electricity consumption

\subsection{Development of mobile application}

In the process of implementation of the application, the development phase will use an evolutionary prototyping methodology. The evolutionary prototype is based on the idea of developing an early version of the system, displaying it to the user, perfecting it through many stages until an adequate system is developed [18]. Some parts have been saved in this methodology as planning, analysis, design, development, and implementation. Each process model follows a series of steps unique to its type to ensure success in the software development process [19]. After the planning, the analysis phase of the review is done. In this phase, the prototype will be developed. If necessary improvement is needed, the process will start again. For this application, two prototypes have been developed, which is the basic starting before continuing to improve. After the approval of this application then it will be forwarded to the next phase. The process produces a final application that will start. Once everything is complete, the implementation will take over. Any review that has been provided will be collected to ensure that the user is satisfied with the application in the wake. Figure 6 to Figure 13 show the interface of developed mobile application, namely as Homebot [14].

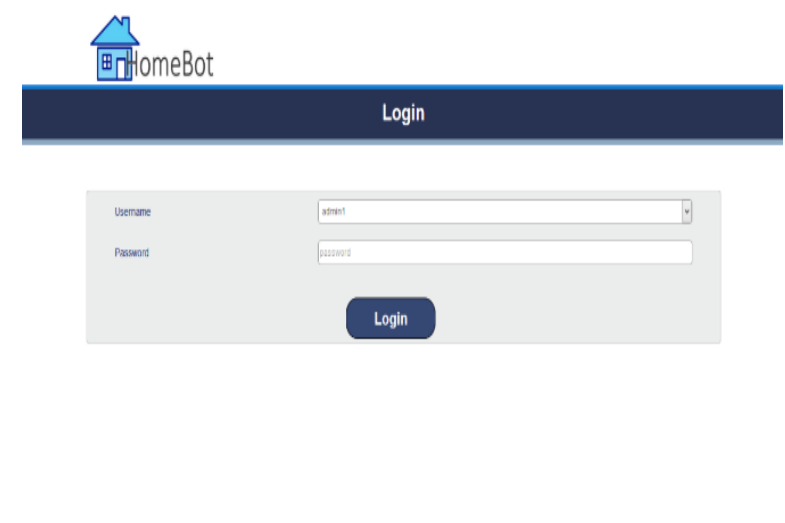

Figure 6. Login page

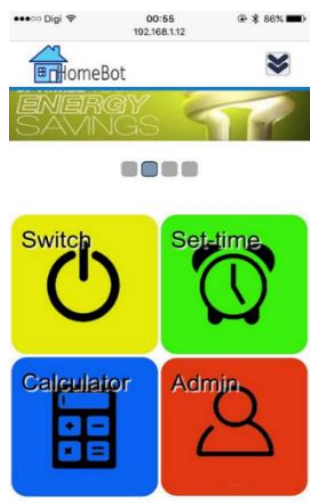

Figure 7. Homepage of HomeBot 


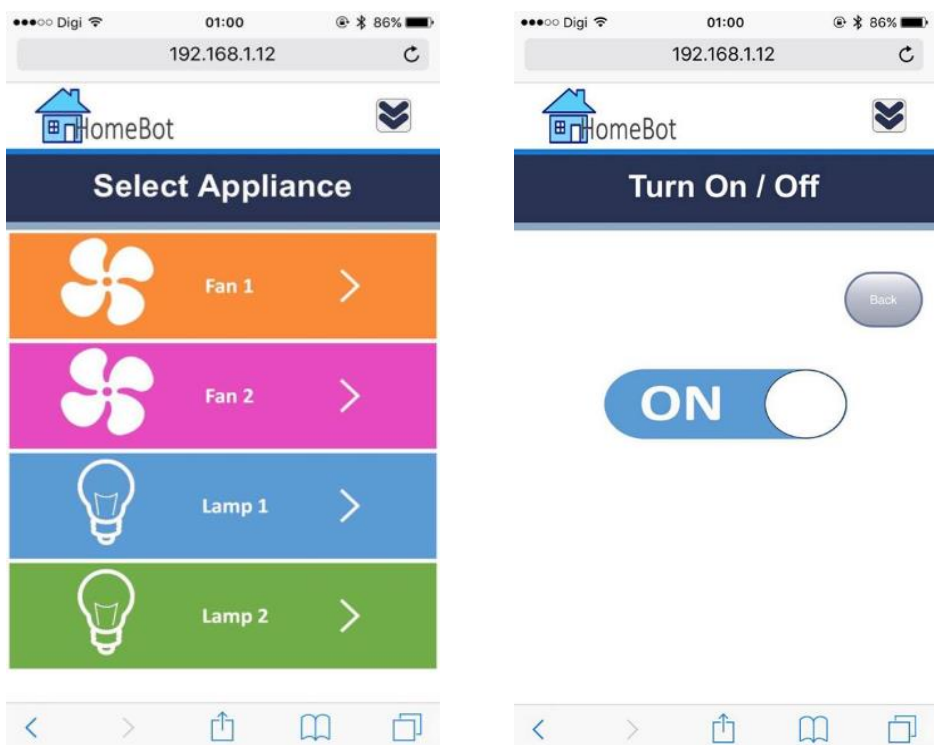

Figure 8. Four modules of HomeBot

Figure 9. Switch page
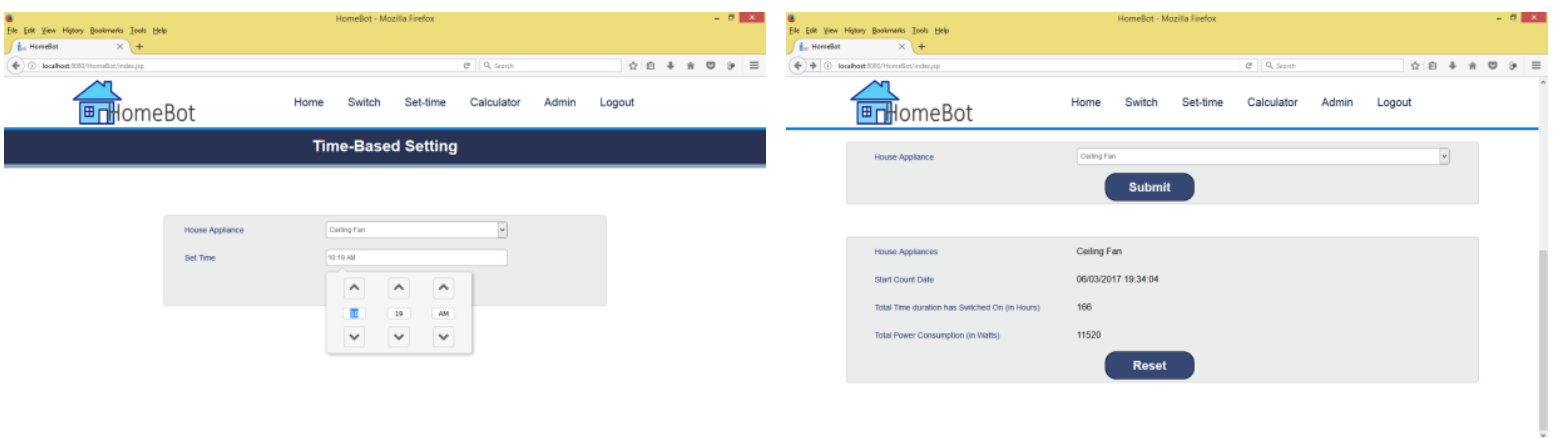

Figure 10. Set-time page

Figure 11. Calculator page

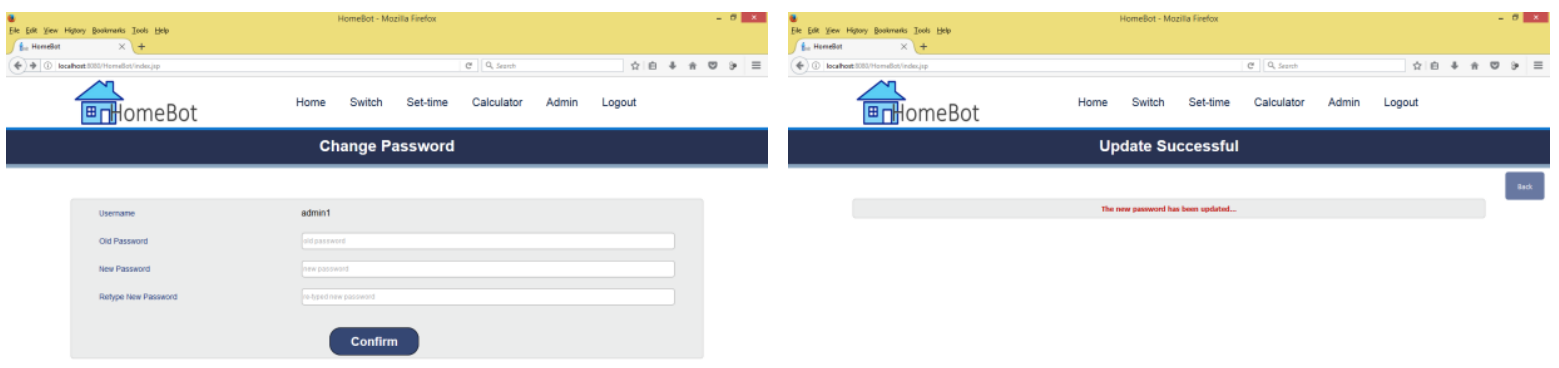

Figure 12. Admin page

Figure 13. Success page

\subsection{User acceptance test}

Expectation-confirmation theory model will be used for user acceptance test (UAT). User acceptance is used to evaluate the system's success factors, which are unclear and low acceptance [20], [21]. This application can be used on the prepared prototype and the target user was find randomly. To make the best result, UAT will be testing with the prepared prototype, a house model to make sure the user is easier to understand how the system works [22]. All the contents in the application are being discussed and some improvements are made. 


\subsection{Data collection}

Survey respondents were the residents of the One Borneo Hypermall Tower A, B and C. The sample consisted of 10 randomly selected participants. Each user has experienced the house appliances controller system through the HomeBot app and controls the ready prototype. After experienced using HomeBot, users were required to fill in a simple survey form.

\section{RESULTS AND DISCUSSION}

Construct validity for the four measurement scales (IS continuance intention, satisfaction, perceived usefulness, and confirmation) was assessed through confirmatory factor analysis (CFA) using the EQS program [23]. Each scale item was modeled as a reflective indicator of the hypothesized latent construct. For models with a good fit, it is suggested that chi-square normalized by degrees of freedom ( ) should not exceed 5 , and the goodness of fit indices NNFI and CFI should both exceed 0.9. The initial measurement model was 2.67 (i.e., 224.3/84), NNFI was 0.88, and CFI was 0.91, suggesting adequate model fit. Table 2 shows the measurement model, which consists of standardized item loading, T-statistic, error loading, item reliability, average variance extracted and composite reliability. However, some factor loadings were below the recommended threshold (i.e., 0.7) and some standardized balances exceeded the recommended cut-off value of 3.0. It is common to find at least some measurement items in models that are estimated to have loads below the 0.7 thresholds in practice. All items seized have a load of at least 0.5 . The measurement model obtained a significant increase in the load index; the model was 1.77 (i.e., 51.26/29), NNFI 0.94, and CFI 0.96 , indicating a suitable model.

Table 2. Measurement model

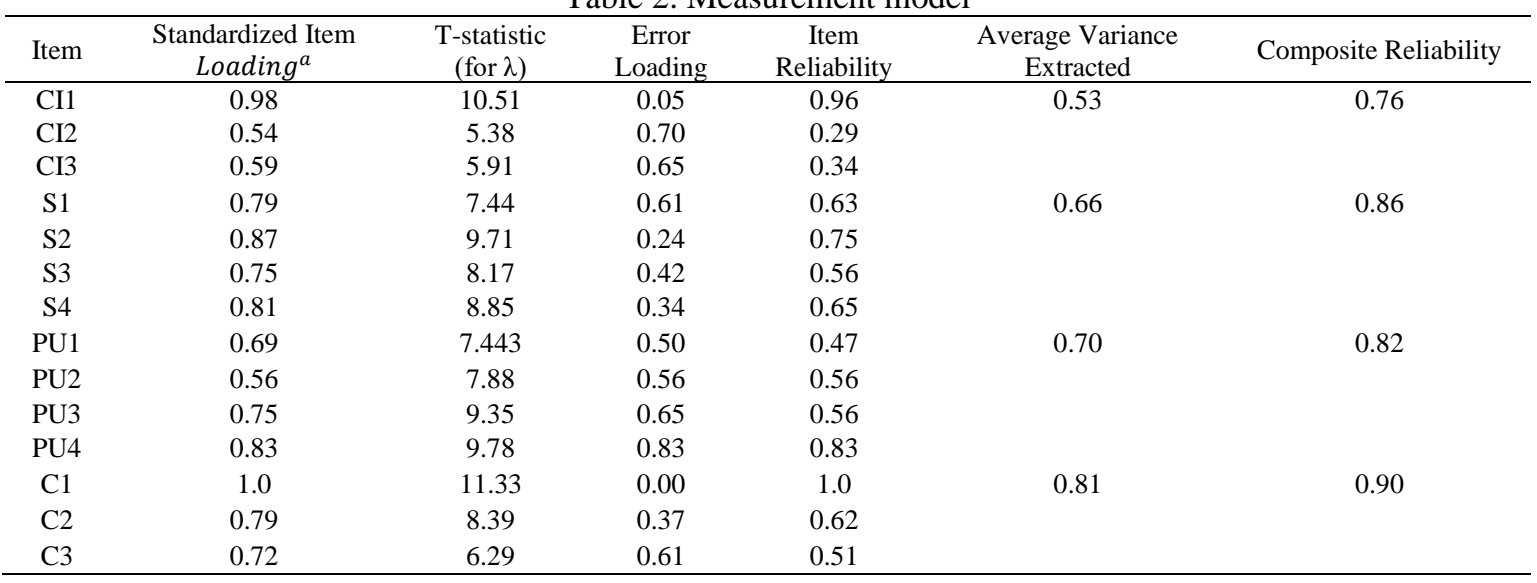

Convergent validity in the final measurement model was assessed using the three criteria suggested by [24]: (1) factor loadings should be significant, (2) construct reliabilities should exceed 0.80, and (3) average variance extracted (AVE) by each construct should exceed the variance due to measurement error (i.e., AVE should exceed 0.50). All factor loading was significant at $\mathrm{p}=0.001$, the cut-off values for the $\mathrm{T}$-statistics $=2$. Construct reliability exceeded 0.80 for two constructs and close to $0.80(0.76)$ for construct continuance intention. AVE ranged from 0.53 to 0.81 , greater than the variance due to measurement errors. Thus, all three conditions for convergent validity were met. To assess the validity of discriminant between constructs, [25] proposed the use of AVE, which is the average variance shared between constructs and their measurements. As shown by Table 3, the AVE values are consistently greater than the diagonal square correlation, indicating discrimination validity satisfactorily at the construct level. Next, each association path significance hypothesized in the model and the variance described by each path (value) were examined. Figure 14 shows the standard path coefficients and path significances. Three of the five hypothesis paths in the model were significant (i.e., at $\mathrm{p}<0.05$ ). The implications of these results for the generalization of the expectation-confirmation model of IS continuity were discussed in the next section. 


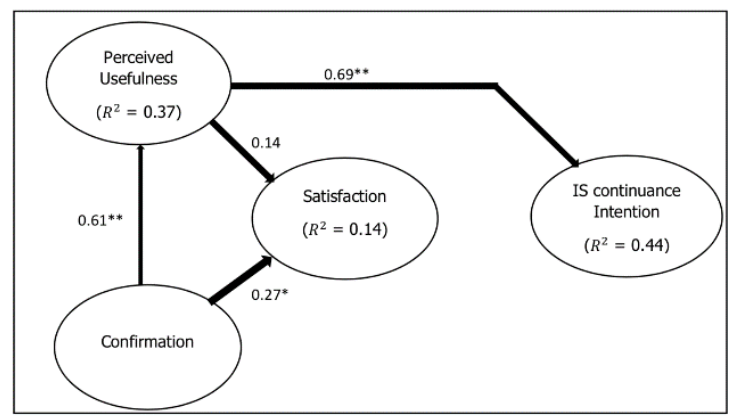

Figure 14. LISREL analysis of research model

Table 3. Squared correlations among constructs and average variance extracted

\begin{tabular}{ccccc}
\hline & Continuance & Satisfaction & Perceived & Confirmation \\
\hline Continuance & 0.53 & 0.01 & 0.44 & 0.28 \\
Satisfaction & 0.01 & 0.66 & 0.08 & 0.13 \\
Perceived & 0.44 & 0.08 & 0.70 & 0.31 \\
Confirmation & 0.28 & 0.13 & 0.31 & 0.81 \\
\hline
\end{tabular}

Note: Path significance: $* * \mathrm{p}<.001, * \mathrm{p}<.05$

Path significance: $* * \mathrm{p}<.001, * \mathrm{p}<.05$

As shown by Table 4, perceived usefulness was a moderate predictor of satisfaction and continuity intentions while only predicting continuance intentions. The fact that perceived usefulness seems to be an important predictor of continuance intentions is unexpected because perceived usefulness consistently influences user intention across the temporary stages of IS use. However, the lack of a relationship between satisfaction and continuance intention in this outcome study was surprising. Thus, this may indicate that instrumental beliefs are more important than feelings to form continuance intentions. A closer examination of the findings suggests that an important path can be taken from confirmation through perceived usefulness and towards continuance intentions. The message from the findings to HomeBot is that HomeBot should first gather communication information about the benefits of using a home-to-home appliance controller system. During the analysis, users should gather experienced users on using home appliance controller system solutions more effectively. Figure 15 shows the proposed model of HomeBot after completed the users' acceptance testing with the expectation confirmation theory model method.

Table 4. Result study

\begin{tabular}{cc}
\hline Path & Current Result Study \\
\hline Perceived Usefulness -> IS Continuance Intention & 0.69 \\
Satisfaction -> IS Continuance Intention & $-0.09^{\text {ns }}$ \\
Perceived Usefulness -> Satisfaction & $0.14^{\text {ns }}$ \\
Confirmation -> Satisfaction & 0.27 \\
Confirmation -> Perceived Usefulness & 0.61 \\
\hline
\end{tabular}

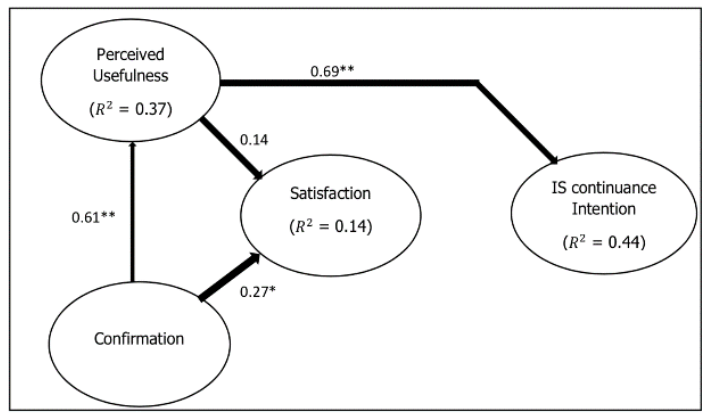

Figure 15. Proposed model of HomeBot 


\section{CONCLUSION}

The motivation to start this project is related to the household's electricity overconsumption and high housebreaking cases in Malaysia. As expected, these problems have been solved. To solve the household's electricity overconsumption, HomeBot is available with the function of power usage monitoring, which helps the users monitor each and every house appliances' power consumption. The second problem, housebreaking cases, is designated high, which HomeBot helps control the house appliances even the house owner is not at home. HomeBot can control the house lights or house security alarm to get attention from the neighbour if housebreaking cases occur. For users' acceptance testing, ECT Model has been used to evaluate the users' acceptance towards HomeBot and the result is ECT can be used to apply on HomeBot. Since this system includes hardware and the software part, the software part is modified and improved to achieve users' expectations. However, the hardware part still has a lot of space to be improved. To produce a perfect HomeBot, software and hardware must be matched to each other such as minimizing the size of hardware and build in the remote control into the house appliances. Re-produce the house appliances specifically used by HomeBot. Therefore, HomeBot is not just focused on software; it is also focused on the productivity of HomeBot's house appliances. Finally, as for the future work for the project, new requirements of the function will be done to improve this application later. All these new requirements will be improved on this application and benefits for the users who are interested in using HomeBot.

\section{REFERENCES}

[1] A. Baharum et al., "Mobile Learning Application: Flipped Classroom," Indonesian Journal of Electrical Engineering and Computer Science (IJEECS), vol. 17, no. 2, pp. 1084-1090, Feb. 2020, doi: 10.11591/ijeecs.v17.i2.pp1084-1090.

[2] A. Baharum, R. Ismail, D. D. I. Daruis, N. F. Fabeil, I. A. Ahmad Bahar, and M. Bahar, "Construction and Evaluation of a User Interface Acceptance Questionnaire," Journal of Theoretical and Applied Information Technology, vol. 96, no. 14, 2018.

[3] A. Baharum, E. A. Rahim, R. Hanapi, N. A. Mat Noor, and N. M. Mohd Yusop, "Evaluating gender-based mobile shopping application using eye-tracking technology," Indonesian Journal of Electrical Engineering and Computer Science (IJEECS), vol. 13, no. 3, pp. 1095-1101, Mar 2019, doi: 10.11591/ijeecs.v13.i3.pp1095-1101.

[4] A. Baharum, S. H. Tanalol, C. Xu Jian, M. Omar, N. A. Mat Noor, and N. M. Mohd Yusop, "Stress catcher application for mobile stress monitoring using questionnaire-based," Indonesian Journal of Electrical Engineering and Computer Science (IJEECS), vol. 16, no. 2, pp. 917-924, Nov. 2019, doi: 10.11591/ijeecs.v16.i2.pp917-924.

[5] D. Hanafi, K. K. Kamaruddin, H. A. Rahman, and Y. Gunardi, "Homestay save rent method through consumer self-management of electricity power consumption," International Journal of Power Electronics and Drive Systems (IJPEDS), vol. 11, no. 1, pp. 425-432, Mar. 2020, doi: 10.11591/ijpeds.v11.i1.pp425-432.

[6] Q. Liu and X. He, "Using Mobile App To Facilitate English Learning For College Students In China," Undergraduate Thesis, School of Business and IT, University of Boras, 2014.

[7] T. Kubota and S. Ahmad, "Energy Efficient City In Malaysia Wind Flow In Neighborhood AREAS," The 6th International Seminar on Sustainable Environment Architecture (SENVAR), 2007.

[8] G. Guangsheng, "A study of Carbon Emission Right Allocation Under Climate Change [J]," Advances in Climate Change Research, vol. 2, no. 6, pp 301-305, 2006.

[9] Overseas Security Advisory Council, "Malaysia 2019 Crime \& Safety Report," Overseas Security Advisory Council, Mar 21, 2019. https://www.osac.gov/Country/Malaysia/Content/Detail/Report/8b419ebf-ea84-4242-b938$15 f 4 a e b 947 e 9$.

[10] Merriam-Webster, The Merriam-Webster Dictionary Revised Edition. Merriam-Webster Mass Market, 2015.

[11] Houghton, The American Heritage Dictionary of the English Language. Boston: Houghton Mifflin Harcourt, 2016.

[12] American Dialect Society, “App' voted 2010 word of the year by the American Dialect Society (UPDATED)," American Dialect Society, Jan 08, 2011. https://www.americandialect.org/app-voted-2010-word-of-the-year-by-theamerican-dialect-society-updated.

[13] S. Ludwig, "Study: Mobile app usage grows 35\%, TV \& web not so much," VentureBeat, Dec 05, 2012. https://venturebeat.com/2012/12/05/mobile-app-usage-tv-web-2012/.

[14] A. Baharum, N. H. Mat Zain, I. Ismail, Y. F. Chew, S. H. Tanalol, and M. Omar, "Utilizing Smartphone and Tablet for Appliances Mobile Controller System," Lecture Notes in Electrical Engineering (LNEE), vol. 488, pp. 273-283, 2018, doi: 10.1007/978-981-10-8276-4_26.

[15] A. Baharum and A. Jaafar, "User Interface Design: A Study of Expectation-Confirmation Theory," in Proceedings of the 5th International Conference on Computing and Informatics (ICOCI 2015), Aug 2015, Istanbul, Turkey, Universiti Utara Malaysia, 2015.

[16] A. Bhattacherjee and G. Premkumar, "Understanding Changes in Belief and Attitude toward Information Technology Usage: A Theoretical Model and Longitudinal Test," MIS Quarterly, vol. 28, no. 2, p. 229, 2004, doi: $10.2307 / 25148634$.

[17] C. Zhao, S. Niu, and X. Zhang, "Effects of household energy consumption on environment and its influence factors in rural and urban areas," Energy Procedia, vol. 14, pp. 805-811, 2012, doi: 10.1016/j.egypro.2011.12.1015. 
[18] T. Kubota, S. Jeong, D. Hooi Chyee Toe, and D. R. Ossen, "Energy Consumption and Air-Conditioning Usage in Residential Buildings of Malaysia," in 11th International Conference on Sustainable Environment Architecture (SENVAR), Surabaya, 2011, pp. 61-69.

[19] G. Lenz and T. Moeller, .NET - A Complete Development Cycle. USA: Addison-Wesley, 2005.

[20] A. Thakur, D. Singh, and V. Chaudry, "Comparing Various SDLC Models On The Basis Of Available Methodology," International Journal Of Modern Engineering Research, vol. 5, no. 3, pp. 34-39, 2015.

[21] M. K. Alsmadi, "The students' acceptance of learning management systems in Saudi Arabian Universities," International Journal of Electrical and Computer Engineering (IJECE), vol. 10, no. 4, pp. 4155-4161, Aug 2020, doi: 10.11591/ijece.v10i4.pp4155-4161.

[22] A. Baharum, S. M. Amirul, N. M. M. Yusop, S. Halamy, N. F. Fabeil, and R. Z. Ramli, "Development of Questionnaire to Measure User Acceptance Towards User Interface Design," Advances in Visual Informatics, vol. 10, no. 4, pp. 531-543, 2017, doi: 10.1007/978-3-319-70010-6_49.

[23] A. Baharum, R. Ismail, D. D. I. Daruis, N. F. Fabeil, I. A. A. Bahar, and M. Omar, "Construction and Evaluation of a User Interface Acceptance Questionnaire," Journal of Theoretical and Applied Information Technology, vol. 96, no. $14,2018$.

[24] P. M. Bentler, Los Angeles: BMDP Statistical Software. EQS Structural Equations Program Manual, 1989.

[25] J. Henseler, C. M. Ringle, and M. Sarstedt, "A new criterion for assessing discriminant validity in variance-based structural equation modeling," Journal of the Academy of Marketing Science, vol. 43, no. 1, pp. 115-135, Aug 2014, doi: 10.1007/s11747-014-0403-8.

\section{BIOGRAPHIES OF AUTHORS}

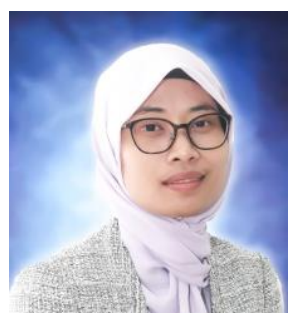

Aslina Baharum PhD Visual Informatics (UKM), MSc IT (UiTM), BSc (Hons.) E-Commerce (UMS) Ts. Dr. Aslina Baharum is a Senior Lecturer at the Faculty of Computing and Informatics, Universiti Malaysia Sabah. She leads the User Experience Research Lab research group in FCI. She has published several books of chapters (6), technical papers in conferences and peer-reviewed and indexed journals $(>50)$ papers. She also served as editor for several journals, and scholarly contributed as committee for conferences, editorial team and manuscript reviewers and also invited to be session chair in conferences. Her research interests are in Human-Computer Interaction, Visual Informatics, Multimedia, User Experience, Mental Model, Eye-tracking, Software Engineering, Mobile Application, Information Technology, ECommerce, Entrepreneurship. She also Certified Professional Entrepreneurial Educator, and Certified Executive Entrepreneurial Leaders. Currently, she appointed as a member of Young Scientist Network, Academy Science Malaysia (2019-2021). aslina@ums.edu.my

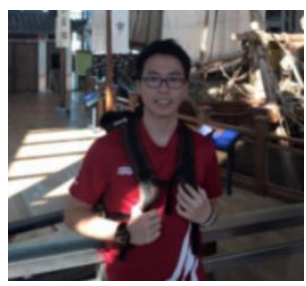

Chew Yun Fai Identify Specialist at Azimuth Labs Pte Ltd, Gelang Patah, Johor, Malaysia Bachelor of Computer Science with Honours in Software Engineering, Universiti Malaysia Sabah (UMS). Chew Yun Fai graduated from Universiti Malaysia Sabah in 2017. He join Azimuth Labs Pte Ltd, Singapore as Associate Identity Specialist in 2017. He promoted as Identity Specialist in 2018. Currently the Team Lead of Identity Access Management projects danny_931117@hotmail.com

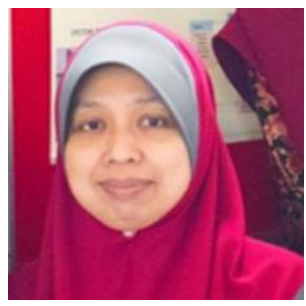

Rozita Ismail Ts. Dr. Rozita Ismail is a senior lecturer in the College of Computing and Informatics, Universiti Tenaga Nasional. Her research interest includes Human-Computer Interaction/UX, Interface Design, Dyslexia and UAV. She has published over 30 publications including journals and international proceedings indexed by Scopus. She currently holds the portfolio as Head of IT postgraduate programs in the College of Graduate Studies, UNITEN. irozita@uniten.edu.my

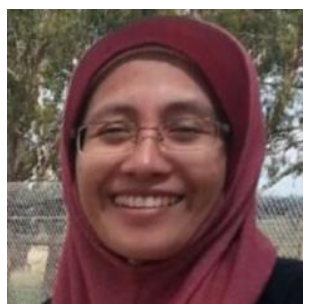

Ismassabah Ismail PhD in Information Technology and Quantitative Sciences, Universiti Teknologi MARA (UiTM), Malaysia, Master in Computer Science (Multimedia), University of Malaya and Bachelor in Information Technology (Hons)(Multimedia), Universiti Utara Malaysia. Currently, Ismassabah Binti Ismail (PhD) is a Senior Lecturer at Centre of Foundation Studies, UiTM Cawangan Selangor, Kampus Dengkil since August 2019. Previously she was posted at Faculty of Computer \& Mathematical Sciences, UiTM Melaka, Kampus Jasin and Faculty of Computer \& Mathematical Sciences, UiTM Shah Alam for five years each. She is being in academic line for more than 20 years since 1998 and posted as lecturer in IUCTT and UNIKL before joining UiTM in 2005. She is an author in the field of multimedia learning, digital storytelling and educational game. She has published about 32 original articles in the finest journals and conferences. She also won 18 awards in research and innovation competition 
regarding her area. She is actively involved as paper reviewer for conferences and journal, jury for various innovation competitions, external book manuscript reviewer, committee for conferences and invited as chairperson for conferences parallel session. She also actively involved in community service as invited speaker. Her research interests include (but not limited) Information and Communication Technology in Culture, Civilisation and Islamic Content, Digital Storytelling, Multimedia and Mobile Application in Education, Game Based Learning, Virtual Reality and Augmented Reality in Education, Mobile User Interface, Information Visualization, Thematic Analysis and Heuristic Evaluation. ismassabah@uitm.edu.my

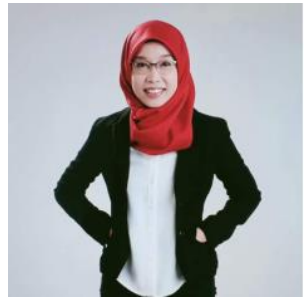

Farhana Diana Deris Senior Lecturer at the Faculty of Social Sciences and Humanities, Universiti Teknologi Malaysia. She currently holds the portfolio as Manager of International Alliances at the office of UTM International. Her current administrative role covers, among others, the coordination of the university's participation in alliances. She also holds executive roles for a number of alliances including as the Coordinator for the Asia Technological University Network, Secretary for the ASEAN Learning Network, and being the university's Erasmus+ Institutional Coordinator. Previously, she was the Head of Microsite Management for MyLinE, the national English language learning portal. She teaches Description of English as part of the Master's TESL programme, and several other courses for the undergraduate degree programme (Computer Assisted Language Learning, Language Games in the Classroom, and Academic Skills for Teachers of ESL). She also teaches English language proficiency programmes (Academic English Skills, Advanced Academic Skills, and English for Professional Purposes). Her research interests include technology enhanced teaching and learning for engaging 21st century English language learners, and building and sustaining partnerships through new media communication in the context of HEI internationalisation. She is also actively involved in student leaders' activities as the Advisor for the UTM ACES Toastmasters Club and the Sabah's Student Representatives. diana@utm.my

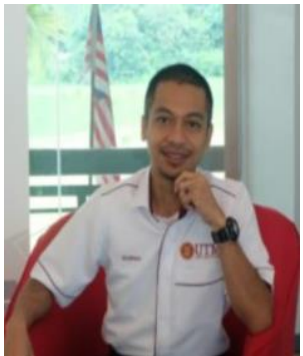

Noorsidi Aizuddin bin Mat Noor Doctor of Philosophy in Built Environment (Property Economics) Property \& Planning, QUT Master in Science Real Estate, UTM Bachelor of Estate Management (Hons.) Estate Management (UM) Noorsidi Aizuddin Mat Noor (Sr Dr.) is a Senior Lecturer at Universiti Teknologi Malaysia and has obtained a Doctorate $(\mathrm{PhD})$ in the Built Environment from Queensland University of Technology, Australia in year 2014. The Real Estate Economics is his main field since his involvement as an academia began in year 2007. He graduated with a Bachelor (Hons.) Estate Management (Malaya University, Malaysia) and holds a Master of Science in Real Estate (Universiti Teknologi Malaysia, Malaysia).noorsidi@utm.my 